Research paper

\title{
Investigation on the thermal degradation and kinetic parameters of innovative insulation materials using TGA-MS
}

\author{
Khaled Chetehouna a, ${ }^{\text {, }}$, Naïma Belayachi ${ }^{\text {b }}$, Borja Rengel a , Dashnor Hoxha ${ }^{\text {b }}$, \\ Philippe Gillard ${ }^{\mathrm{c}}$ \\ a INSA-CVL, Univ. Orléans, PRISME EA 4229, F-18022 Bourges, France \\ ${ }^{\mathrm{b}}$ Univ. Orléans, INSA-CVL, PRISME, EA 4229, Orléans, France \\ ${ }^{c}$ Univ. Orléans, INSA-CVL, PRISME EA 4229, F-18000 Bourges, France
}

\section{H I G H L I G H T S}

- Two kind of straw and two others of binder have employed to design four composites.

- TGA-MS technique was used to investigate thermochemical behaviors of materials.

- The mass losses of the insulation materials are mostly influenced by the binder.

- The highest amount of gas in pyrolysis products has a $m / z$ ratio of $28(>2 / 3)$.

\section{A R T I C L E I N F O}

\section{Article history:}

Received 30 August 2014

Accepted 16 February 2015

Available online 24 February 2015

\section{Keywords:}

Straw composites

Thermal insulation

TGA-MS

Thermal degradation

Kinetic parameters

\begin{abstract}
A B S T R A C T
Thermogravimetric analyzer coupled to a mass spectrometer (TGA-MS) was used to study the thermochemical behavior of eight samples. Two varieties of straw (wheat and barley) and two others of binder (lime and plaster) have employed to design four composites. These composites can be considered as innovative insulation materials for buildings. The thermal degradation of the different specimens was studied from a temperature of 50 to $1000^{\circ} \mathrm{C}$ using increased temperature of $20^{\circ} \mathrm{C} / \mathrm{min}$. This thermal degradation is an important element to evaluate the fire behavior and predict the evolution of smoke emitted during an accidental fire for building application. Using MS analyzer, the ion currents evolutions of 16 molecule groups (shared by a $m / z$ ratio) were followed as functions of temperature. TG curves show that the thermal decomposition of composite samples is more complex (3-4 mass loss steps) than the one of the basic materials (1-2 mass loss stages) and seems to be mostly affected by the binder nature. The highest amount of gas in pyrolysis products is associated to $m / z=28$ ratio and presents more than two thirds of the total quantity. The kinetic parameters were evaluated for the more important mass loss of each sample and their values are in the ranges of $8.29-64.86 \mathrm{~kJ} / \mathrm{mol}, 0.4-3.36$ and $1.78 \times 10^{3}$ $-1.63 \times 10^{7} \mathrm{~min}^{-1}$ for respectively the activation energy, the reaction order and the pre-exponential factor.
\end{abstract}

() 2015 Elsevier Ltd. All rights reserved.

\section{Introduction}

Green building materials have become a major issue due to their several interesting properties. Indeed, they are cost-effective, bio-degradable and durable eco-friendly construction material

\footnotetext{
* Corresponding author. INSA Centre Val de Loire - Campus de Bourges, Laboratoire PRISME UPRES EA 4229, 88, Boulevard Lahitolle, CS 60013, 18022 Bourges Cedex, France. Tel.: +33248484065.

E-mail address: khaled.chetehouna@insa-cvl.fr (K. Chetehouna).
}

that will meet the global needs of thermal rehabilitation. These composite materials consist of two or more components with natural fibers in order to obtain specific characteristics such as compressive strengths, high tensile, and reduce shrinkage and cracking. Some literature works show that it is possible to produce high performance natural fiber composite based on different matrix. Millogo et al. [1] show that the fiber size has an impact on the compressive behavior of the composite based clay matrix. Indeed with the longer fibers the thermal conductivity and the compressive strength decreases which is favorable for insulation building application. Other authors [2] have also investigate 
coconut fiber reinforced concrete with cement matrix for earthquake resistant housing concerns. They show also that the pullout energy increase with the increase in embedment length, rope diameter, cement and fiber content. To improve the strength and the durability of high performance concrete in aggressive environment, Ramli et al. [3] have incorporate coconut-fiber at four different contents for different exposure environment. By considering the parameters studied in this experimental investigation the researchers recommend the fiber content of $1.2 \%$ for the longterm strength. Although the application and the use of the composite are different in these examples, the addition of natural fibers has a positive effect. In the comparative study of PachecoTorgal [4], the use of lightweight materials based natural fibers are more suitable for non-structural parts of the building like thermal insulation but this is not the only factor of sustainable development. The study include also other important factors in building sector, the materials for mitigating building cooling, materials with reduced embodied energy and materials capable of reusing a high waste content. Concerning natural fibers, some studies highlight that straw bales are excellent construction materials as well as energy efficient and even fire-resistant. Several investigations have been performed to study the effect of humidity and temperature on the one hand on thermal conductivity [5] and the other on equilibrium moisture content [6] of coating plaster used for straw bales construction. In the two cases, three different fiber types wheat straw, barley straw and wood shavings are mixed with clay and sand. The results indicate that the thermal conductivity of the coating plaster decreases with increasing fiber content and decreasing sand content. Unfortunately, the majority of works on straw bales construction is at the straw bale scale and need more accurate laboratory testing in order to understand the behavior at the level of the straw fibers. Thermal degradation and evolved species of these innovative green composites must be studied before their use in building applications. Over the last decades, thermogravimetric analysis (TGA), where changes in weight are measured as a function of increasing temperature, has been widely used in different research fields. For example the combustion behavior of different coals is investigated to understand the combustion process and evaluate the effect of their properties on its thermal and combustion behavior with the objective of the use of low-quality coals to meet the high consumption demand [7,8]. Other researchers have studied the combustion behavior and pollutant emissions of biomass in order to evaluate the environmental impact of the biofuel production [9] or for produce and characterize the bio-oil based on thermal decomposition of cottonseed [10]. Singh et al. [11] used TGA analysis for the assessment and the characterization of volatiles components in the case of the waste incineration. TGA and DSC analysis are used also for other important research area like aerospace technology by Nna-Mvondo et al. [12] for studied thermal stability of laboratory Titan tholin. Moreover, in the building area where the research of new materials with good thermal performances to increase the thermal energy storage in buildings is very active, thermal analysis (ATG, DSC) are used to show thermal stability and determine the phase changing behavior of the cement composite with Lauryl alcohol/kaolin [13] and clay or gypsum composite with polyethylene glycol [14]. Data obtained from thermogravimetric analysis apparatus provides great insight into thermodynamic aspects of the thermal behavior of materials. In addition to mass loss, the combination of a TGA with a Mass Spectrometer (MS) allows to quantify compounds in the off-gas in real-time to provide an extremely powerful tool for the materials characterization and their interactions with environment. The description of TGA-SM apparatus and kinetic analysis of this study are given in the next section.
The main purpose of this paper is to investigate the thermal degradation, the kinetic parameters and the released gases of construction material composed of binders (lime or plaster) and cereal straw fibers (wheat or barley) at small scale. This investigation is carried out using a Thermogravimetric Analyzer coupled to a Mass Spectrometer (TGA-MS). When heated, straw composite materials could endure a thermal degradation and emit different pollutant gases. Besides their thermal insulation performance, straw composites should lead a slight loss of mass and low pollutants emission when the temperature increases. The TGA-MS measurements presented in Section 3 will permit to classify the different prepared samples according to their mass loss and pollutant gases emissions. In order to correlate the straw composites thermal degradation and released gaseous emissions to the ones of the basic components, the four basic components (binders: lime or plaster and straw fibers: wheat or barley) are preliminary studied. This research is an important step for the proposed material in relation to the technical and sanitary regulations for building application.

\section{Material and methods}

\subsection{Straw-concrete preparation}

The utilization of cereal straw is motivated by its large availability and its porous microstructure offering a good thermal property. It is also natural agricultural residue grown during a half or one-year period. Straw is produced in excess to requirement, so it is cheap and easily accessible. While the seed is processed for different food industries, the biomass left behind tends to be a problem. Traditionally, straw has been used for animal bedding or burned by farmers because of the storage conditions. Thus, the research program proposes a new solution of original low cost construction material for the valorization of this lost material. Before preparing the composites, a first investigation is performed on the physical properties of straw. Then, two types of straw were selected and investigated for the composite, wheat and barley fibers. In order to facilitate the molding process, short straw fibers were used. The choice of the binder type is of great importance and complexity. It must answer an easy mixer, a perfect coating of fibers, a correct molding and a final composite with good mechanical and thermal properties. In this case of study, two types of binders were selected and investigated for the composite, lime and plaster.

Four mixtures named $\left(\mathrm{F}_{2, \mathrm{LW}}, \mathrm{F}_{2, \mathrm{LB}}, \mathrm{F}_{3, \mathrm{~PB}}\right.$ and $\left.\mathrm{F}_{3, \mathrm{PW}}\right)$ are investigated in this paper. All specimens were prepared using an optimized water/binder $(\mathrm{W} / \mathrm{B})$ ratio of 1.1 and straw fibers/binder ratio of 0.2 and 0.4 . The manufacture procedure was firstly investigated by Belayachi et al. [15] using different W/B and S/B ratios with the aim of finding the best compromise between thermal and mechanical performance for the insulation material. Among many mixtures tested the straw composite with low thermal conductivity and good mechanical properties is one with a W/B ratio of 1.1 for both the two types of binders (lime and plaster) and fibers (wheat and barley). The optimal S/B ratio is different for lime and plaster respectively 0.2 and 0.4 . The standard procedure used for mortars giving a poor result for the composite, it was necessary to investigate on a process of mixing natural fibers with lime or plaster to obtain homogeneous samples. Briefly, it consists of a first mixture of the straw fibers with $20 \%$ of the water for $60 \mathrm{~s}$, followed by the addition of the mixed binder-water and mixing for $5 \mathrm{~min}$. The binder was mixed with $80 \%$ of the water prior to addition in the mixer in order to obtain a good binder/fiber mixture. Fig. 1 shows the different composite materials which are $\mathrm{F}_{2, \mathrm{LW}}$ (wheat/lime with a $S / B$ ratio of 0.2 ), $F_{2, \text { LB }}$ (barley/lime with a $S / B$ ratio of 0.2 ), $F_{3, P B}$ (barley/plaster with a $\mathrm{S} / \mathrm{B}$ ratio of 0.4 ) and $\mathrm{F}_{3, \mathrm{PW}}$ (wheat/plaster with 


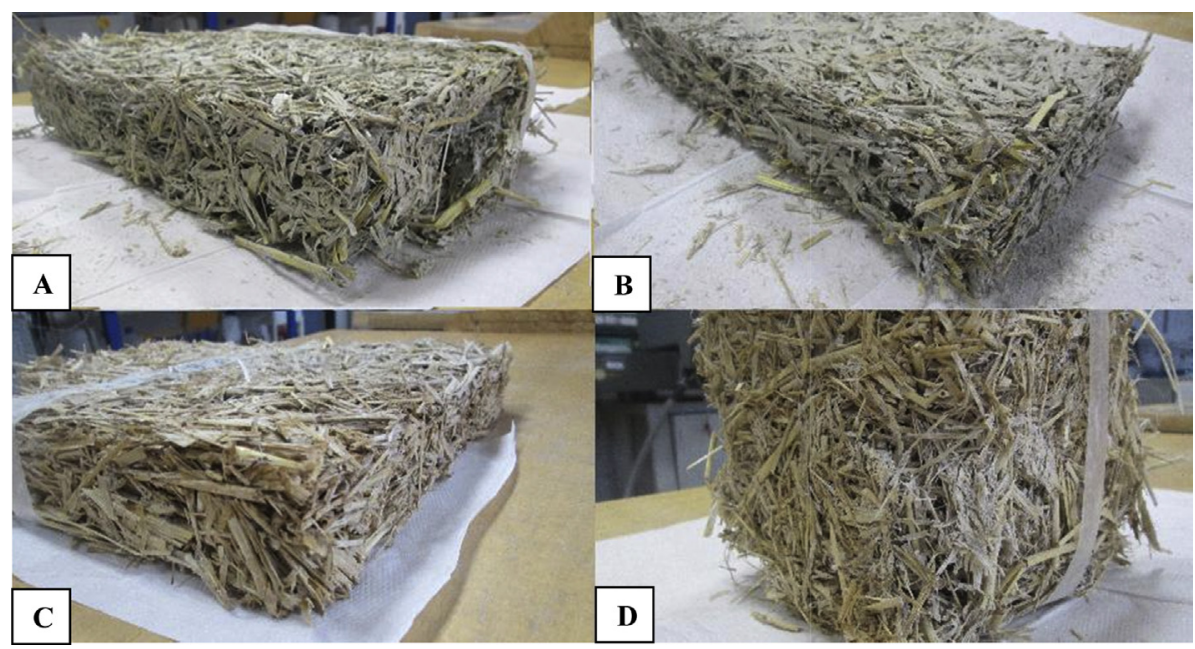

Fig. 1. The lightweight straw-concrete materials: (A) $F_{2, \mathrm{LB}}$; (B) $F_{2, \mathrm{LW}}$; (C) $F_{3, \mathrm{~PB}}$; (D) $\mathrm{F}_{3, \mathrm{PW}}$.

a S/B ratio of 0.4 ). Before the thermal degradation study, the specimens are drying in cure room at $20{ }^{\circ} \mathrm{C}$ and humidity of $56 \%$ during 28 days according to the mortar procedure.

\subsection{TGA-MS experiments}

As indicated in the introduction, thermogravimetric analyzer coupled to a mass spectrometer (TGA-MS) is an analysis technique that permits to follow the mass loss and the released gases during the thermal degradation of a material. In this study, a Setsys $16 / 18$ Setaram thermobalance was coupled to a Balzers QMS 200 mass spectrometer. The measurements were performed under an inert argon atmosphere. Samples of $5 \mathrm{mg}$ were placed in an alumina crucible and heated from ambient temperature to $1000{ }^{\circ} \mathrm{C}$ with a heating rate of $20{ }^{\circ} \mathrm{C} / \mathrm{min}$. Volatile gases produced during the thermal degradation were transported to mass spectrometer through a heated transfer line maintained at $150{ }^{\circ} \mathrm{C}$ in order to avoid their condensation. The mass spectrometer was operated at $70 \mathrm{eV}$ and a scan of the $m / z$ was performed from 1 to $150 \mathrm{amu}$. The ion curves close to the noise level were neglected and only the intensities of 16 selected ions $(m / z=1,2,14,16,17,18,19,27,28,29$, $30,32,34,40,44,45)$ were followed by the mass spectrometer. Among these intensities, we observed that only 3 ones $(m / z=17,18$, 44) vary when the temperature increased. For different experiments, the background signal (which corresponds to the initial gas concentration in the mass spectrometer) was subtracted to the measurement. To ensure the repeatability, each experiment was carried out at least three times. Fig. 2 illustrates a picture and a schematic overview of the experimental setup.

\subsection{Kinetic analysis}

Depending on the type of data used, the kinetic analysis methods can be classified into two categories: model-fitting and model-free isoconversional [16]. The first class evaluates the data assuming a kinetic reaction model $f(\alpha)$. For this kind of approach, only one thermogravimetric measurement is necessary obtained from a single heating rate. However, some studies have demonstrated that a single analysis is typically unreliable and tends to produce kinetic parameters without relevance. Despite this lack of reliability, it is a fast method to get the possible values for the kinetic parameters [17]. Couto et al. [18] proposed a numerical model using Eulerian-Eulerian approach to analyze the municipal solid waste gasification. In order to take into account kinetic effects, they include the Arrhenius rate. The second class of kinetic analysis methods is a viable alternative to the first one because it requires any assumption about the analytical form of the reaction model. However, several experiments at different heating rates to evaluate the kinetic parameters are needed which is the major drawback of this type of methods. In this work, the method of Liu and Fan [19]

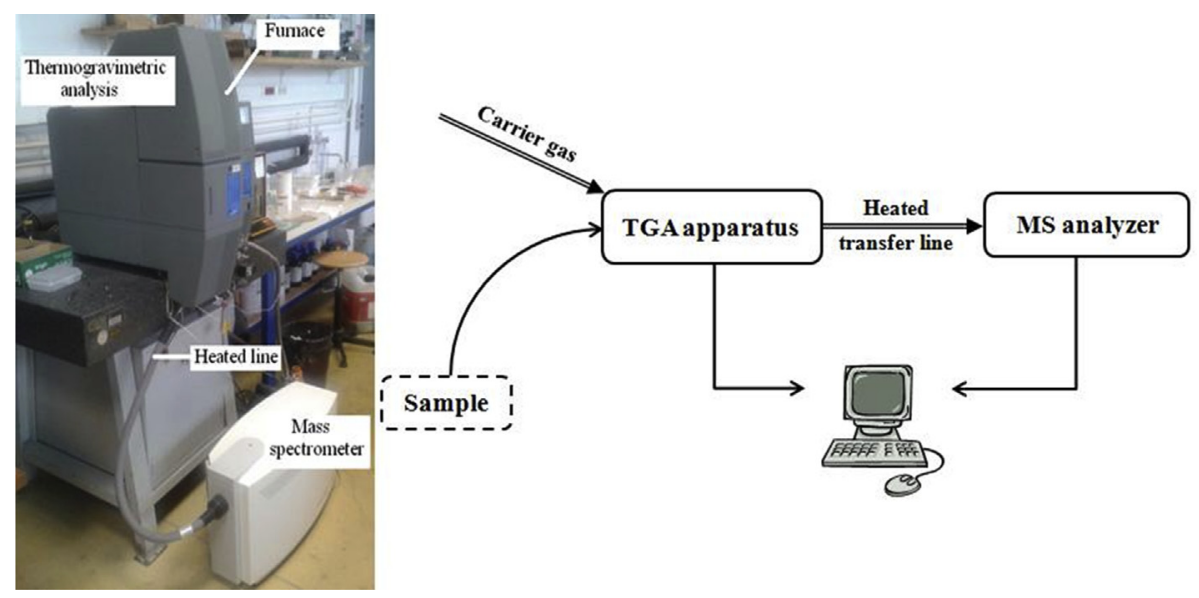

Fig. 2. Picture and schematic overview of TGA-MS experimental setup. 

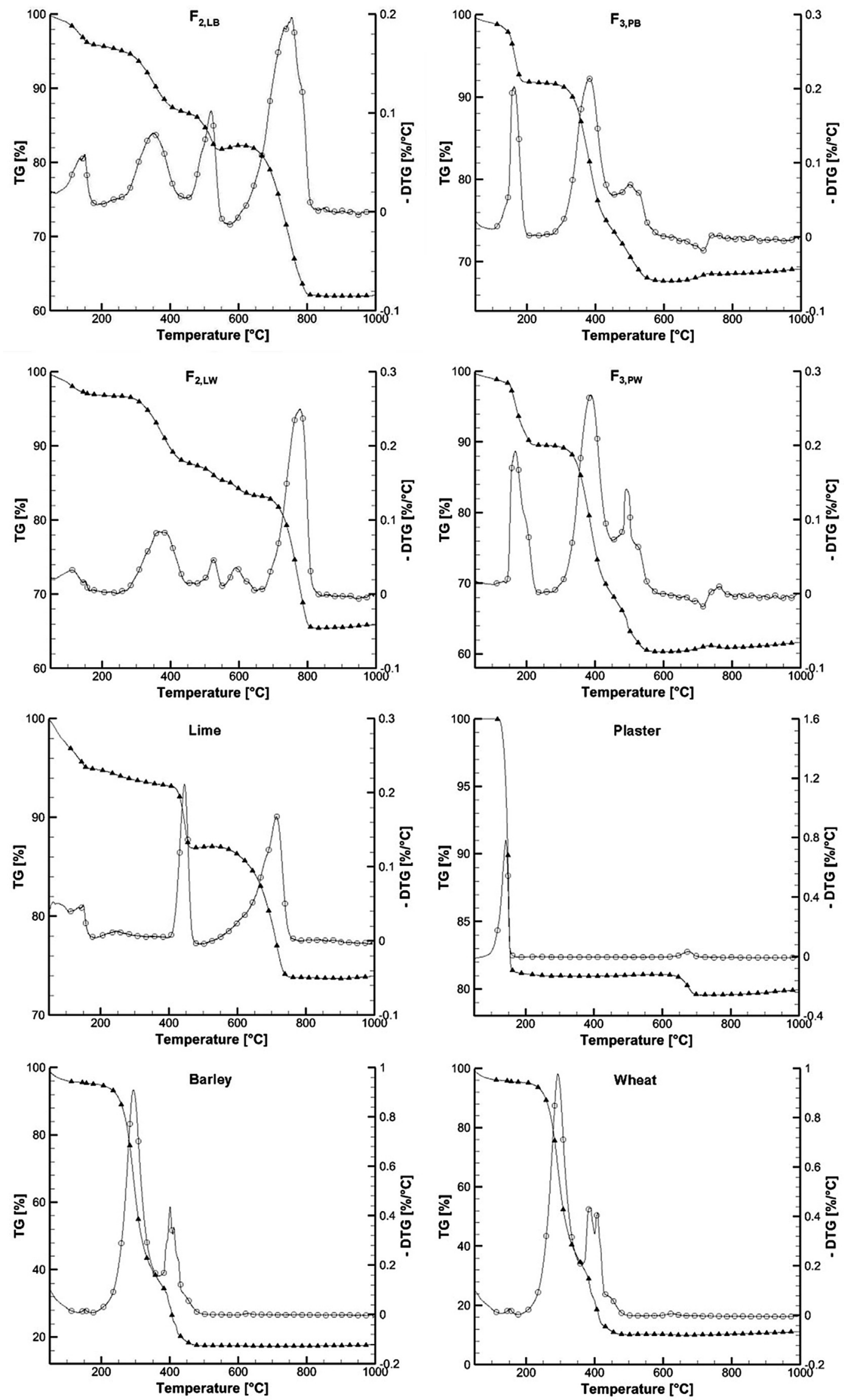

Fig. 3. Evolutions of TG and -DTG as functions of temperature for different straw fiber composites and basic materials: ( $\boldsymbol{\Delta}$ ) TG curves and ( $O$ ) - DTG curves. 
has been chosen to determine the kinetic parameters of the different samples because it is a simple and fast method that requires only one heating rate. For sake of clarity, the principal steps of this method are detailed in the following.

First we define a reaction model $f(\alpha)$ as follows:

$f(\alpha)=(1-\alpha)^{n}$

where $\alpha$ is the fraction of sample decomposed at time $t$ and $n$ is the order of the reaction. This fraction of sample, which is a mass ratio, can be written as:

$\alpha=\frac{m(t)-m_{0}}{m\left(t_{\max }\right)-m_{0}}$

with $m(t)$ the mass evolution of the sample over time, $m_{0}$ the initial sample mass and $m\left(t_{\max }\right)$ the sample mass at the maximum temperature. The defined reaction model of relation (1) combined with the Arrhenius law's permit to obtain the following empirical relationship:

$$
\frac{d \alpha}{d t}=A(1-\alpha)^{n} \exp \left(\frac{-E_{a}}{R T}\right)
$$

where $A$ is the pre-exponential factor, $E_{a}$ is activation energy of reaction, $R$ is the perfect gases constant and $T$ is the temperature. Introducing the heating rate $\beta$, Equation (3) becomes:

$\frac{d \alpha}{d T}=\frac{A}{\beta}(1-\alpha)^{n} \exp \left(\frac{-E_{a}}{R T}\right)$

Taking logarithms of both sides of Equation (4), we obtain:

$\ln \left(\frac{d \alpha}{d T}\right)=\ln \left(\frac{A}{\beta}\right)-\frac{E_{a}}{R T}+n \ln (1-\alpha)$

Applying the differential operator $\Delta$ and some mathematical rearrangements to the above equation, three following relationships can be obtained:

$\frac{\Delta \ln (d \alpha / d T)}{\Delta \ln (1-\alpha)}=-E_{a} \frac{\Delta(1 / T)}{R \Delta \ln (1-\alpha)}+n$

$\frac{\Delta \ln (1-\alpha)}{\Delta \ln (d \alpha / d T)}=\frac{E_{a}}{n} \frac{\Delta(1 / T)}{R \Delta \ln (d \alpha / d T)}+\frac{1}{n}$

$\frac{\Delta[\ln (d \alpha / d T) / \ln (1-\alpha)]}{\Delta[1 /(T \ln (1-\alpha))]}=\ln \left(\frac{A}{\beta}\right) \frac{\Delta[1 / \ln (1-\alpha)]}{\Delta[1 /(T \ln (1-\alpha))]}-\frac{E_{a}}{R}$

Using experimental sample fraction $\alpha$ and temperature $T$ data from TGA curves, these equations permit to estimate the kinetic parameters of the different samples $E_{a}, n$ and $A$ respectively.

\section{Results and discussion}

As indicated in the above section, the thermal decomposition of composite materials elaborated in laboratory which are dedicated to building applications as well as their basic components is investigated in this paper. Thermal degradation of the materials and the combustion of the emitted gases is a complex phenomenon which is at the origin of a fire. It is a process where several reactions occur simultaneously. Therefore, it is essential to know the thermokinetic characteristics to accurately predict the fire behavior and study the fire-resistance of materials. These parameters provide information about the fire intensity and allow the proposition of the reaction scheme in fire simulation. The pyrolysis phenomenon is modeled by means of an Arrhenius law in open-source and inhouse CFD fire codes [20,21]. Consequently, the main interest of this work is to obtain the kinetic parameters of the materials using TGA measurement.

Pollutant gases emissions results and the kinetic parameters values of the different materials (binders, fibers and the four composite materials) are also studied in this work. Fig. 3 illustrates the mass loss (TG [\%] $\left.=100 \times m(t)-m_{0} / m_{0}\right)$ and its negative derivation with respect to temperature $\left(-\mathrm{DTG}\left[\% /{ }^{\circ} \mathrm{C}\right]=-d \mathrm{TG} /\right.$ $d T$ ) for the different straw fiber composites and their basic components. Important data in the kinetic studies are the onset temperature of degradation, temperature and mass loss of the end of the phenomenon. Regarding this Figure, it seems that the mass loss and its derivative with respect to temperature of each straw composite material are mostly influenced by the binder nature. Indeed, straw/lime composites $\left(F_{2, \mathrm{LB}}\right.$ and $\left.\mathrm{F}_{2, \mathrm{LW}}\right)$ are mainly characterized by four thermal degradation steps associated to the -DTG peaks reached at temperatures about: 150, 350, 520 and $750{ }^{\circ} \mathrm{C}$. The most important mass loss of these composites (about 15\%) is related to the last thermal degradation step which happens in temperature range $640-810{ }^{\circ} \mathrm{C}$. Straw/ plaster composites ( $\mathrm{F}_{3, \mathrm{~PB}}$ and $\left.\mathrm{F}_{3, \mathrm{PW}}\right)$ are principally characterized by three thermal decomposition stages related to the -DTG peaks achieved at temperatures about: 170,380 and $490{ }^{\circ} \mathrm{C}$ and the highest mass loss value (about 15\%) occurs in temperature interval of $330-430^{\circ} \mathrm{C}$. Concerning the basic materials, it is clear that straws present similar thermal degradation behavior which reveals two main steps in the two temperature ranges $220-320^{\circ} \mathrm{C}$ and $320-420{ }^{\circ} \mathrm{C}$. The mass loss of the first decomposition step is about 2.5 times more important than the one of the second step. Both types of straw (barley and wheat) contain a high percentage of cellulose which in component with the most material capable of being emitted as gases in the first step of the degradation process where the mass loss is important. The obtained results of wheat and barley straws are in good agreement with those of Ergüdenler and Ghaly [22] and Wang et al. [23]. The thermal decomposition behavior of lime is very different to the one of plaster. In fact, it is characterized by two degradation steps in the temperature intervals of $400-450{ }^{\circ} \mathrm{C}$ and $550-750{ }^{\circ} \mathrm{C}$ whereas the mass loss of plaster presents only one main thermal decomposition step in the temperature range $100-200{ }^{\circ} \mathrm{C}$. Although there are very few data on binders in the literature, Gonzalez et al. [24] studied the thermal behavior of plaster with polyurethane foam wastes and obtain a similar TG curve. Their work highlights that the principal mass loss is associated to water molecules coming from $\mathrm{CaSO}_{4} \cdot 2 \mathrm{H}_{2} \mathrm{O}$ decomposition. To finish the Figure discussion, it is clear that the most significant mass loss of straw/lime composites is originally

Table 1

Released species ion current percentage of basic and composite materials.

\begin{tabular}{lllll}
\hline Material & \multicolumn{4}{l}{ Released species ion current percentage [\% wt.] } \\
\cline { 2 - 5 } & $m / z=14$ & $m / z=28$ & $m / z=32$ & Others \\
\hline Straws & & & & \\
Barley & 5.09 & 72.15 & 16.15 & 6.61 \\
Wheat & 8.24 & 70.24 & 15.11 & 6.41 \\
Binders & & & & \\
Lime & 8.44 & 70.28 & 14.74 & 6.53 \\
Plaster & 8.61 & 69.94 & 14.85 & 6.6 \\
Composite & & & & \\
$\mathrm{F}_{2, \mathrm{LB}}$ & 8.38 & 69.54 & 15.72 & 6.36 \\
$\mathrm{~F}_{2, \mathrm{LW}}$ & 8.05 & 68.87 & 16.27 & 6.82 \\
$\mathrm{~F}_{3, \mathrm{PW}}$ & 7.92 & 71.35 & 14.40 & 6.34 \\
$\mathrm{~F}_{3, \mathrm{~PB}}$ & 7.53 & 69.73 & 16.76 & 5.98 \\
\hline
\end{tabular}


Straw fiber composites
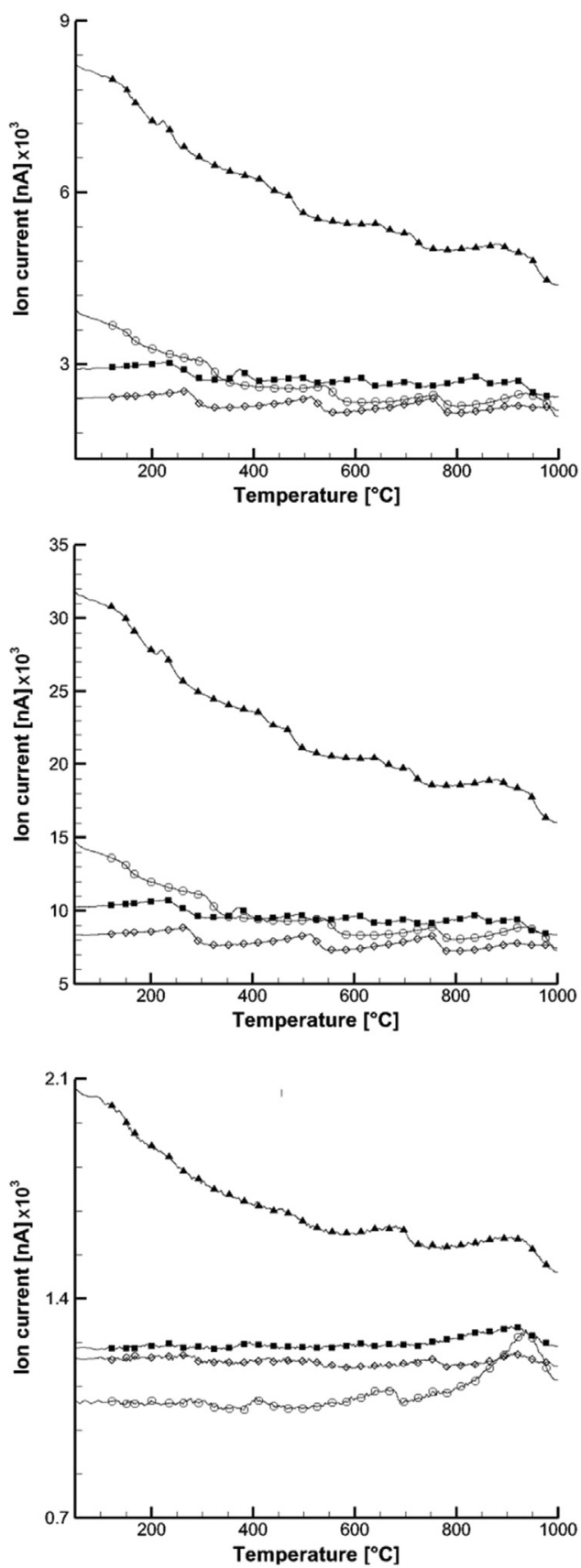

Basic materials

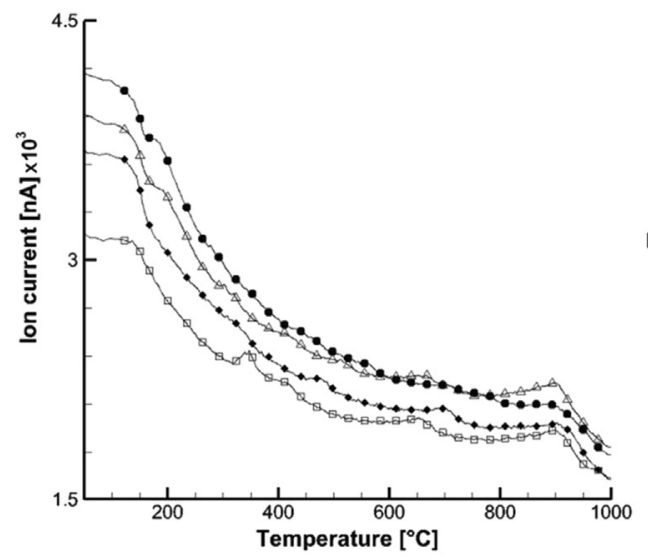

$\mathrm{m} / \mathrm{z}=17$

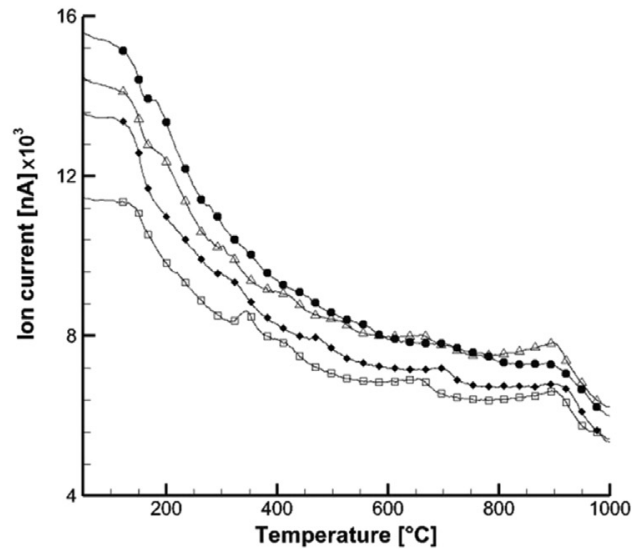

$\mathrm{m} / \mathrm{z}=18$

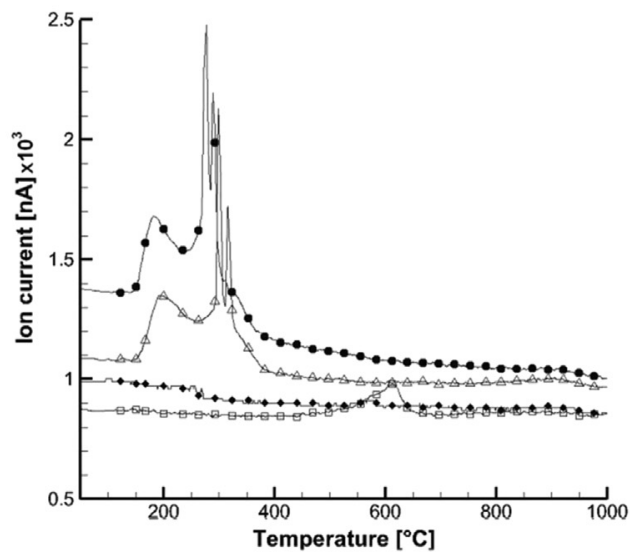

Fig. 4. Ion current evolutions of three species $(m / z=17,18$ and 44$)$ for basic and composite materials and $(\square)$ Lime.

from the second -DTG lime peak whereas the main mass loss of plaster is correlated to the first peak of straw/plaster materials.

Profiles of TGA curves show an important mass loss for composite based plaster than one based lime mixed with barley or wheat for the last step of degradation. Despite that the cellulosic material shows a significant mass loss during the first stage of the thermal degradation, the composite shows a reverse manner to decompose. The binder plays a role in delaying the char formation in the composite.

Mass spectrometer results of basic and composite materials are given in Table 1. This Table shows three species ion current percentages $(m / z=14,28,32)$ higher than $5 \%$ wt. and not vary when temperature increase. It is evident regarding the different values that the most important released molecules are $m / z=28$ (about 70\%) followed by $m / z=32$ (about 15\%) after that $m / z=14$ (about 5-9\%). It's also noticed that this behavior is the same for basic and composites materials. The last column of Table 1 presents ion current percentages of the other species. Among these molecules, only three of them with $m / z=17,18$ and 44 have variations of ion current as function of temperature. Fig. 4 illustrates the ion current evolution of these three species versus temperature for different straw/binder composites and their basic materials. 
This Figure reveals that the ion current values of molecules with $m / z=18$ (which can be corresponded to $\mathrm{H}_{2} \mathrm{O}$ ) are about 4 times higher than the ones of $m / z=17$ (which can be attributed to $\mathrm{OH}$ or/ and $\mathrm{NH}_{3}$ ) for the different materials. The ion current values evolution of species with $m / z=17,18$ and 44 (which can be assigned to $\mathrm{CO}_{2}$ and/or $\mathrm{C}_{3} \mathrm{H}_{8}$ ) as function with temperature has the same behavior for the different straw fiber composites. This behavior is characterized by an important decrease of ion current of $F_{2, L W}$ and slight variations of the other straw/binder composites when temperature increased. For basic materials, the ion currents related to $m / z=17$ and 18 have the same tendency which can be described by an ion current decreased with increasing temperature. Nevertheless, the ion current evolutions of the molecules $(m / z=44)$ released by straws are characterized by two peaks (at 200 and $300{ }^{\circ} \mathrm{C}$ ) whereas those emitted by binders present mild variations of ion currents.

The last part of this section deals with the kinetic parameters of basic and straw fiber composites. Table 2 presents the activation energy $E_{a}$ and the order of reaction $n$ as well as the preexponential factor $A$ for wheat, barley, lime, plaster and straw/ binder composites. These kinetic parameters are evaluated for the more significant mass loss associated to the different samples. Regarding this Table, we can notice that the activation energy value of barley is about 1.5 times more important than the one wheat. The same observation can be found in the straw/plaster composite materials. These composites have activation energy values 2-3 times smaller than the ones of straw/lime materials. The lime binder presents an energy activation value in order of magnitude of the ones of straw/lime composites (about $60 \mathrm{~kJ} / \mathrm{mol}$ ) whereas plaster has the lowest value $(8.29 \mathrm{~kJ} / \mathrm{mol})$. Table 2 shows also that the reaction order values are in range of $0.4-3.36$ and the ones of the pre-exponential factor $A$ are between $1.78 \times 10^{3}$ and $1.63 \times 10^{7} \mathrm{~min}^{-1}$. The results show that the activation energy of lime is hardly changed by adding wheat and barley, conversely, plaster shows a significant increase of this energy with the addition of straw. We can say that the chemical reaction will be faster for the plaster composite than the lime one.

In summary, this work represents initial work into thermal degradation and the immediate continuity is underway to take into account these kinetic parameters for the fire prediction of the elaborated straw composite.

\section{Conclusion}

In this paper, we have elaborated four composite materials by means of two straws and binders. For construction applications, these innovative composites are good candidates for the thermal insulation. The thermal degradation and the mass spectrometer analysis as well as the kinetic parameters determination have been

Table 2

Kinetic parameters values of basic and composite materials.

\begin{tabular}{lcll}
\hline Material & $E_{a}(\mathrm{~kJ} / \mathrm{mol})$ & $n$ & $A\left(\mathrm{~min}^{-1}\right)$ \\
\hline Straws & & & \\
Wheat & 31.65 & 2.94 & $7.72 \times 10^{5}$ \\
Barley & 48.46 & 1.93 & $3.38 \times 10^{4}$ \\
Binders & & & \\
Lime & 60.10 & 1.35 & $1.73 \times 10^{4}$ \\
Plaster & 8.29 & 0.76 & $1.63 \times 10^{7}$ \\
Composites & & & \\
$\mathrm{F}_{2, \mathrm{LB}}$ & 60.22 & 0.40 & $1.78 \times 10^{3}$ \\
$\mathrm{~F}_{2, \mathrm{LW}}$ & 64.86 & 2.12 & $4.15 \times 10^{5}$ \\
$\mathrm{~F}_{3, \mathrm{PW}}$ & 20.12 & 3.36 & $1.31 \times 10^{4}$ \\
$\mathrm{~F}_{3, \mathrm{~PB}}$ & 32.41 & 2.47 & $8.51 \times 10^{4}$ \\
\hline
\end{tabular}

studied. Obtained results exhibit that there are differences between the thermal behaviors the straw/lime materials and the ones of straw/plaster composites. These differences are materialized by the number of mass loss steps, their percentages and their temperature ranges. The analysis of the pyrolysis products shows that the main chemical group emitted by these composites and their basic materials is characterized by a $m / z=28$ ratio with a percentage of about 70\%. In the future, we will extend this work to a large range of this composite materials varying straw/binder ratio. The behavior of the prepared composites submitted to different flame retardants will be also investigated. A numerical investigation is underway for the prediction of fire behavior of insulation materials by using the kinetic parameters determined in this study.

\section{Acknowledgments}

Authors would like to acknowledge especially Léo COURTY for his help in performing the TGA-MS analyses.

\section{References}

[1] Y. Millogo, J.C. Morel, J.E. Aubert, K. Ghavami, Experimental analysis of Pressed Adobe Blocks reinforced with Hibiscus cannabinus fibers, Constr. Build. Mater. 52 (2014) 71-78.

[2] M. Ali, N. Chouw, Experimental investigations on coconut-fibre rope tensils strength and pullout from coconut fibre reinforced concrete, Constr. Build. Mater. 41 (2013) 681-690.

[3] M. Ramli, W.H. Kwan, N.F. Abas, Strength and durability of coconut-fiberreinforced concrete in aggressive environments, Constr. Build. Mater. 38 (2013) 554-566.

[4] F. Pacheco-Torgal, Eco-efficient construction and building materials research under the EU Framework Programme Horizon 2020, Constr. Build. Mater. 51 (2014) 151-162.

[5] T. Ashour, H. Wieland, H. Georg, F.J. Bockisch, W. Wu, The influence of natural reinforcement fibers on insulation values of earth plaster for straw bale buildings, Mater. Des. 31 (2010) 4676-4685.

[6] T. Ashour, H. Goerg, W. Wu, An experimental investigation on equilibrium moisture content of earth plaster with natural reinforcement fibers for straw bale buildings, Appl. Therm. Eng. 31 (2011) 293-303.

[7] S.G. Sahu, A. Mukherjee, M. Kumar, A.K. Adak, P. Sarkar, S. Biswas, H.P. Tiwari, A. Das, P.K. Banerjee, Evaluation of combustion behaviour of coal blends for use in pulverized coal injection (PCI), Appl. Therm. Eng. 73 (2014) 1014-1021.

[8] C. Moon, Y. Sung, S. Ahn, T. Kim, G. Choi, D. Kim, Thermochemical and combustion behaviour of coals of different ranks and their blends for pulverizedcoal combustion, Appl. Therm. Eng. 54 (2013) 111-119.

[9] C.R. Coronado, J.A. Carvalho Jr., C.A. Quispe, C.R. Sotomonte, Ecological efficiency in glycerol combustion, Appl. Therm. Eng. 63 (2014) 97-104.

[10] E. Apaydin-Varol, B.B. Uzun, E. Onal, A.E. Pütün, Synthetic fuel production from cottonseed: fast pyrolysis and a TGA/FT-IR/MS study, J. Anal. Appl. Pyrolysis 105 (2014) 83-90.

[11] S. Singh, C. Wu, P.T. Williams, Pyrolysis of waste materials using TGA-MS and TGA-FTIR as complementary characterization techniques, J. Anal. Appl. Pyrolysis 94 (2012) 99-107.

[12] D. Nna-Mvondo, J.L. de la Fuente, M. Ruiz-Bermejo, B. Khare, C.P. McKay, Thermal characterization of Titan's tholins by simultaneous TG-MS, DTA, DSC analysis, Planet. Space Sci. 85 (2013) 279-288.

[13] S.A. Memon, T.Y. Lo, X. Shi, S. Barbhuiya, H. Cui, Preparation, characterization and thermal properties of Lauryl alcohol/Kaolin as novel form-stable composite phase change material for thermal energy storage in buildings, Appl. Therm. Eng. 59 (2013) 336-347.

[14] A. Sari, Composites of polyethylene glycol (PEG600) with gypsum and natural clay as new kinds of buildings PCMs for low temperature-thermal energy storage, Energy Build. 69 (2014) 184-192.

[15] N. Belayachi, M. Bouasker, D. Hoxha, M. Al-Mukhtar, Thermo-Mechanical behavior of an innovate straw lime composite for thermal insulation applications, Appl. Mech. Mater. 390 (2013) 542-546.

[16] P.J. Skrdla, Dynamical considerations for kinetic methods in thermal analysis, J. Phys. Chem. Solids 74 (2013) 1375-1379.

[17] V. Tihay, P. Gillard, Pyrolysis gases released during the thermal decomposition of the three Mediterranean species, J. Anal. Appl. Pyrolysis 88 (2010) $168-174$.

[18] N. Couto, V. Silva, E. Monteiro, S. Teixeira, R. Chacartegui, K. Bouziane, P.S.D. Brotto, A. Rouboa, Numerical and experimental analysis of municipal solid wastes gasification process, Appl. Therm. Eng. 78 (2015) 185-195.

[19] N.A. Liu, W.X. Fan, Critical consideration on the Freeman and Carroll method for evaluating global mass loss kinetics of polymer thermal degradation, Thermochim. Acta 338 (1999) 85-94. 
[20] K. McGrattan, S. Hostikka, J. Floyd, H. Baum, R. Rehm, W. Mell, R. McDermott Fire, Dynamics Simulator (Version 5): Technical Reference Guide, NIST Special Publication 1018-5, 2010, p. 118.

[21] Y. Ding, C. Wang, S. Lu, Large Eddy simulation of fire spread, Procedia Eng. 71 (2014) 537-543.

[22] A. Ergündeler, A.E. Ghaly, A comparative study on the thermal decomposition of four cereal straws in an oxidizing atmosphere, Bioresour. Technol. 50 (1994) 201-208.
[23] C. Wang, Y. Wu, Q. Liu, H. Yang, F. Wang, Analysis of the behavior of pollutant gas emissions during wheat straw/coal cofiring by TG-FTIR, Fuel Process. Technol. 92 (2011) 1037-1041.

[24] S.G. Gonzalez, J. Gadea, A. Rodriguez, C. Junco, V. Calderon, Lightweight plaster materials with enhanced thermal properties made with polyurethane foam wastes, Constr. Build. Mater. 28 (2012) 653-658. 